\title{
Artritis facetaria séptica en paciente joven sin factores de riesgo
}

\section{Septic facet arthritis in young patient without risk factors}

\author{
Aland G. Bisso-Andrade'
}

Bisso-Andrade A.Artritis facetaria séptica en paciente joven sin factores de riesgo. Rev Soc Peru Med Interna. 202 I;34(3): I I0-I I3.

https://doi.org/10.36393/spmi.v34i3.611

\section{RESUMEN}

Se reporta el caso de un varón de 22 años que presentó lumbalgia aguda grave sin respuesta a los analgésicos comunes. El estudio por resonancia magnética mostró un proceso inflamatorio en la articulación facetaria T8-T9 y una pequeña colección epidural. Se realizó drenaje con aguja bajo control tomográfico y el cultivo de la muestra aisló Streptococcus agalactiae. El paciente evolucionó en forma favorable a la terapia antibiótica administrada, penicilina $\mathrm{G}$ sódica intravenosa durante tres semanas y otros betalactámicos oral por 4 semanas. La infección piógena de las articulaciones facetarias es rara.

Palabras claves: artritis séptica, artritis facetaria, infección espinal, absceso epidural, lumbalgia aguda.

\section{ABSTRACT}

A 22-year-old male who had severe acute low back pain with no response to common analgesics is reported.The MRI study showed an inflammatory process in the T8-T9 facet joint and a small epidural collection. Needle drainage was performed under tomographic control and it was isolated Streptococcus agalactiae the culture of the sample. The patient evolved favorably to antibiotic therapy administered, intravenous sodium penicillin $G$ for 3 weeks and other beta-lactam agents orally for 4 weeks. Pyogenic infection of the facet joints is rare.

Keywords: septic arthritis, facet arthritis, spinal infection, epidural abscess, acute low back pain.

\section{INTRODUCCIÓN}

Las articulaciones facetarias son las únicas articulaciones sinoviales de la columna vertebral y pueden verse afectadas por una serie de procesos como espondiloartropatías seronegativas, artritis reumatoide, artropatía por depósito de cristales, gota, infecciones (artritis séptica), osteocondroma, hemangiomas y sarcomas. ${ }^{1}$

Médico internista. Clínica Delgado, Lima, Perú.
La artritis facetaria séptica, o piógena, (AFS) es una condición patológica rara que constituye el $4 \%$ a $20 \%$ de todas las infecciones espinales. La AFS ocurre en la columna lumbar en el $86 \%$ al $97 \%$ de casos, $9 \%$ en la columna cervical y menos del $5 \%$ en la columna dorsal. Afecta en mayor proporción al grupo etario de 57 a 73 años y es ligeramente más frecuente en el hombre. El primer caso se reportó en 1987) y hasta enero del 2020 se reportaron 61 casos. $^{2-4}$

La AFS tiene una presentación clínica similar a la espondilodiscitis y su diagnóstico tardío puede conducir a 
una morbilidad y mortalidad significativas como resultado de diseminación local o sistémica de la infección. La AFS puede pasar desapercibida debido al estudio imagenológico tardío o incompleto, o debido al desconocimiento del espectro de enfermedades que pueden implicar a las articulaciones facetarias. ${ }^{4}$

El cuadro clínico característico es la aparición de un dolor agudo de rápida progresión, moderado a severo, de intensidad creciente. El paciente localiza el dolor sobre la vértebra afectada, el mismo que se incrementa con la palpación y el movimiento. El dolor se irradia hacia una o ambas zonas laterales, genera contractura muscular y limitación funcional. El dolor no calma con el dolor ni en determinada postura, y cuando es intenso no remite con los analgésicos comunes. Otros síntomas asociados son fiebre y malestar general. Dependiendo de la severidad y evolución del proceso, el paciente puede presentar signos radiculares, como paresia o parestesias, o signos de sepsis (hipotensión arterial, fiebre alta, escalofríos). ${ }^{2,4}$

Las infecciones de las articulaciones facetarias son causadas generalmente por el Staphylococcus aureus (70\% a 86\%). La infección es secundaria a la invasión hematógena desde un foco primario, por contaminación a partir de un foco adyacente

(cuerpo vertebral, disco o músculo), por inoculación de la articulación por inyección de corticosteroides, cirugía o traumatismo y por la diseminación de una infección adyacente al espacio articular. Se ha reportado como factores predisponentes para AFS: edad $>60$ años, diabetes. mellitus, inmunosupresión, artritis reumatoide, infección de la piel, uso de drogas intravenosas y manipulación articular previa (incluida la prótesis articular, cirugía articular reciente e inyecciones intraarticulares de corticosteroides). ${ }^{2,4,5}$

El medio diagnóstico de elección para las infecciones espinales piógenas y no piógenas es la resonancia magnética con contraste. La evidencia de un absceso, o cualquier tipo de colección, requiere el drenaje inmediato bajo control de imagen a fin de realizar el estudio microbiológico (Gram y cultivo) y el inicio inmediato de la terapía antibiótica intravenosa. Muy rara vez la infección puede ser de tipo no piógeno, debido a tuberculosis, brucelosis o infección fúngica. ${ }^{6}$

\section{PRESENTACIÓN DEL CASO}

Un varón de 22 años ingresó al servicio de emergencia de la Clínica Delgado manifestando que desde un día antes presentaba dolor dorsolumbar de inicio insidioso, pero de curso rápidamente progresivo. La radiografía de columna lumbar informó una "acentuación de lordosis lumbar y escoliosis dorsolumbar izquierda". Con el diagnóstico presuntivo de lumbalgia mecánica se le aplicó terapia sintomática parenteral con respuesta parcial. El paciente continuó terapia ambulatoria con analgésicos y relajantes por vía oral; sin embargo, el dolor reapareció de manera más intensa y reingresó por emergencia dos días después. Nuevamente, recibió terapia analgésica/antiinflamatoria por vía parenteral, pero como el dolor era muy intenso y la respuesta terapéutica no fue significativa, se indicó su hospitalización.

El paciente manifestaba dolor dorsolumbar intenso 10/10, irradiado a ambas zonas paravertebrales y que no cedía en ninguna posición. Negó fiebre, síntomas gastrointestinales, respiratorios, urinarios o de otras áreas osteoarticulares.

No presentaba antecedentes patológicos de importancia y en lo familiar, solo padre y abuelo paterno habían padecido de litiasis renal.

Al examen físico se encontró a un paciente obeso, en regular estado general, buen estado de hidratación, ansioso y muy quejumbroso.

Funciones vitales: PA 132/88 mm Hg, frecuencia cardiaca 90 latidos/min, frecuencia respiratoria 20 excursiones/min, $\mathrm{SatO}_{2} 98 \%$; Temperatura $37^{\circ} \mathrm{C}$. Peso $110 \mathrm{Kg}$.

La piel no mostró lesiones. Locomotor: limitación funcional en columna dorsolumbar por dolor intenso; dolor a la presión en zona dorsolumbar; contractura muscular paralumbar. Marcada escoliosis de columna. Cavidad oral: mucosa oral y dientes sin alteraciones; faringe y amígdalas sin signos inflamatorios; presencia de material
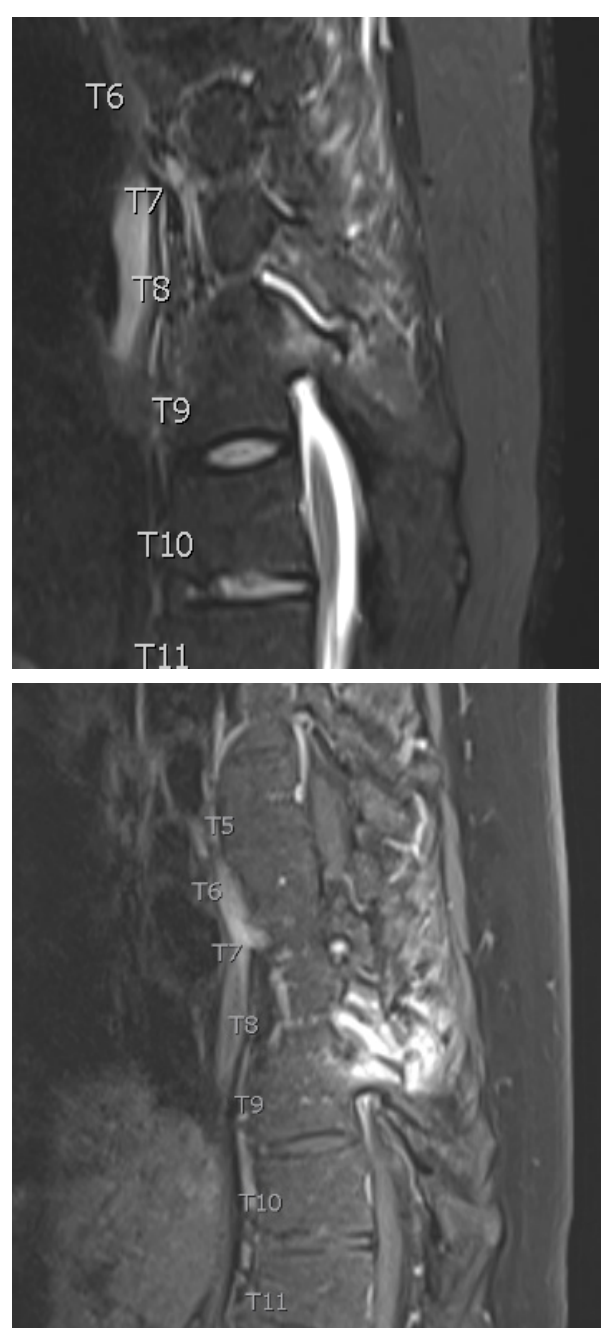

Figura I y 2. RMN: proceso inflamatorio en la articulación facetaria T8-T9 y una pequeña colección epidural 
metálico dental (brackets). Cuello: no adenomegalias, no tiroides palpable. Tórax: Simétrico, murmullo vesicular normal en ambos campos pulmonares. Cardiovascular: ruidos cardíacos rítmicos, no soplos. Abdomen: blando, depresible, no dolor, no masa palpable. Genitourinario: puño-percusión lumbar izquierda positiva. Neurológico: lúcido y orientado, no déficit motor ni sensitivo. Lasègue negativo. Reflejos osteotendinosos normales.

La impresión diagnóstica inicial fue de lumbalgia mecánica aguda, a descartar discopatía, pero por los antecedentes familiares se consideró la posibilidad de cólico renal por litiasis.

Inicialmente el paciente recibió por vía intravenosa: paracetamol $1 \mathrm{~g}$, cada 8 horas, ketoprofeno $100 \mathrm{mg}$, cada 12 horas, tramadol $300 \mathrm{mg}$ en infusión IV para 24 horas y orfenadrina una ampolla intramuscular cada 12 horas. Debido a que la intensidad del dolor no disminuía, se administró tapentadol cada 12 horas y morfina condicional, con los cuales recién disminuyó el dolor a un nivel de 6/10. El hemograma mostró 11500 leucocitos $/ \mathrm{mm}^{3}$ y el PCR 5,7 $\mathrm{mg} / \mathrm{dL}$. Hemoglobina, glucosa, creatinina, perfil hepático y orina, dentro de rangos normales.

La ecografía no reveló signos patológicos, pero por las limitaciones debidas a la obesidad del paciente se solicitó tomografía de vías urinarias, la misma que fue informada como normal. La RMN dorsolumbar con contraste registró el hallazgo de proceso inflamatorio en la articulación facetaria T8-T9 con pequeña colección epidural pósterobilateral, por lo cual se indicó en forma inmediata la punción y drenaje de la articulación facetaria T8-T9, bajo guía tomográfica, con lo cual se obtuvo un $\mathrm{ml}$ de líquido serohemático. El estudio del líquido obtenido informó presencia de 70 leucocitos/campo, >100 hematíes/campo y la tinción Gram mostró cocos grampositivos. Con este resultado se inició de inmediato terapia con oxacilina $2 \mathrm{~g}$ EV cada 4 horas, a fin de cubrir agentes como el $S$. aureus o especies de estreptococo.

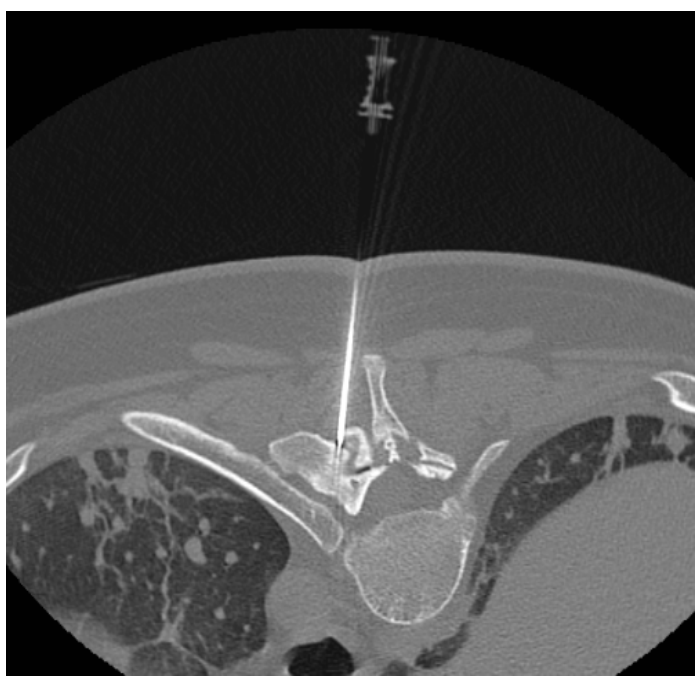

Figura 3. Drenaje con aguja bajo control tomográfico que permitió obtener la muestra para estudio.
En los días siguientes, el paciente presentó mejora sintomática progresiva y el dolor respondió al tramadol sin necesidad de aplicar morfina ni tapentadol.

En el cultivo del líquido drenado se aisló Streptococcus agalactiae por lo cual se suspendió la oxacilina y se indicó penicilina G sódica, 3 millones UI EV cada 4 horas. Una nueva RMN registró persistencia de inflamación facetaria T8-T9, erosión de facetas, edema óseo y ausencia de colección. En los días subsiguientes, el paciente presentó remisión progresiva del dolor hasta volverse asintomático, con mejor ánimo y recuperación del apetito. La evaluación odontológica no halló alteración alguna. El ecocardiograma no registró signos compatibles con endocarditis y fue informado como normal. La radiografía simple de tórax tampoco registró patología broncopulmonar alguna.

Doce días después del ingreso, el hemograma resultó normal y la PCR fue de $0,4 \mathrm{mg} / \mathrm{dl}$. El paciente salió de alta con la indicación de ceftriaxona $2 \mathrm{~g}$, EV cada 24 horas, durante 7 días. En el control ambulatorio, el paciente se presentó asintomático y sin limitación funcional. A fin de completar su terapia antibiótica, luego de tres semanas de antibióticos intravenosos, se indicó amoxicilina $500 \mathrm{mg}$, vía oral, cada 8 horas, durante cuatro semanas. Un control de RMN al mes del alta informó la presencia de signos inflamatorios con menor severidad que los estudios iniciales. Un mes más tarde, el paciente se presentó asintomático y sin limitaciones motoras en columna vertebral. Sus exámenes de hemograma y de PCR resultaron normales.

En resumen, el esquema antibiótico completo fue el siguiente: oxacilina $2 \mathrm{~g}$, IV, cada 4 horas (20 al 23 de setiembre), seguido de penicilina $\mathrm{G}$ sódica 3 millones UI, cada 4 horas ( 24 de setiembre al 02 de octubre), durante la hospitalización. Al alta, recibió en forma ambulatoria: ceftriaxona 2 g, IV, cada 24 horas (3 al 9 de octubre) seguido, finalmente, de amoxicilina $500 \mathrm{mg}$, VO, cada 8 horas, durante 4 semanas.

\section{DISCUSIÓN}

La AFS es rara y solo se reportan casos aislados o series de casos. En uno de los reportes más numerosos, se publicó una serie de 42 casos diagnosticados durante un periodo de 10 años. $^{2}$

El paciente con AFS que se reporta en este artículo fue un joven de 22 años, una edad inusual para esta patología ya que la AFS se presenta en forma predominante en el grupo etario de 60 años a más., ${ }^{2,-9,11}$ Así mismo, llama la atención que nuestro paciente no presentaba factores de riesgo para AFS, como uso de drogas intravenosas, alcoholismo, diabetes, insuficiencia renal en etapa terminal, enfermedad neoplásica subyacente y otras enfermedades con inmunosupresión, que sí aparecen descritos en la mayoría de reportes publicados. . $^{2,9,10,12-15}$

De otro lado, nuestro paciente no presentaba un foco infeccioso concomitante que pueda considerarse la causa primaria de diseminación bacteriana adyacente o hematógena. En una serie de casos, el 36\% presentó otro foco infeccioso concomitante, como artritis infecciosa, 
infección urinaria, endocarditis bacteriana e infección de piel y partes blandas $(5 \%)$, entre otros. ${ }^{2}$

Debido a que, por lo general, el paciente con AFS se presenta inicialmente afebril y sin déficit neurológico, el diagnóstico rara vez se realiza en forma precoz y el paciente recibe solo terapia sintomática. En general, la duración media de los síntomas antes del diagnóstico es de aproximadamente cuatro semanas, con un rango de dos días hasta cinco meses. ${ }^{2,7,9,11,13}$. En nuestro caso, el diagnóstico se realizó a los cuatro días de iniciados los síntomas, durante el segundo día de hospitalización.

Clínicamente, todos los pacientes con ASF presentan dolor de alta intensidad que no encuentra posición antálgica. El segundo síntoma más importante es la fiebre. El caso presentado no registró fiebre durante su evolución, lo cual, comparado a oros reportes, lo caracteriza como como un cuadro atípico de AFS. El caso presentado no registró fiebre durante su evolución. Un estudio encontró fiebre en el $83 \%$ de 42 casos reportados, otro en 9 de 11 casos, y otras series entre 0 a $20 \%$ hasta el $100 \%$ (6/6 casos)., . $7-9,11$ También se reportó un caso de AFS lumbar que, en forma atípica, presentó un cuadro de abdomen agudo. ${ }^{14}$

Respecto al diagnóstico microbiológico, en el presente caso se aisló Streptococcus agalactiae, similar a lo reportado en 3 de 42 casos con AFS (7\%) y en un paciente con AFS y absceso epidural. ${ }^{2,15} \mathrm{Sin}$ embargo, se ha encontrado que $S$. aureus es la bacteria más aislada: $86 \%$ (36/42 casos) y, en una revisión de la literatura, en $81 \%$ de casos; y, en otras publicaciones, $36 \%$ (4/11 casos) y el 50\% (3/6 casos). ${ }^{2,7,9,13}$ En cuanto al manejo terapéutico, el paciente que reportamos recibió tratamiento antibiótico por siete semanas: terapia intravenosa durante tres semanas y terapia ambulatoria por vía oral durante cuatro semanas. Al respecto, en una serie de casos se reportó un promedio de cuatro semanas para la terapia antibiótica parenteral (rango de una a seis semanas), seguido de terapia oral de dos a ocho semanas. Otro estudio reportó una duración total de terapia antibiótica de seis a doce semanas; terapia intravenosa por dos semanas, seguido de terapia oral durante seis semanas; $y$, terapia intravenosa durante un mes y terapia oral por dos meses. ${ }^{2.7 .9 .13}$

Finalmente, nuestro paciente solo requirió aspirado con aguja bajo control tomográfico de la colección epidural y respondió bien a la terapia antibiótica. En este aspecto, en una serie reportada, el $19 \%$ tuvo drenaje con aguja bajo control tomográfico y el $26 \%$ requirió de abordaje quirúrgico abierto debido a complicación neurológica severa. $^{2}$ Un caso reportado de AFS por Streptococcus agalactiae también requirió abordaje quirúrgico abierto por presentar un absceso que se extendía desde T-12 hasta

\section{L-4. ${ }^{15}$}

En conclusión, laAFS es una patología rara cuyo diagnóstico, además, puede ser tardío y llevar a complicaciones neurológicas y sépticas. Se recomienda realizar estudio por imágenes (RMN o tomografía) de la columna, a todo paciente que presente dolor agudo intenso en algún segmento de la columna vertebral y con baja respuesta a la administración parenteral de sintomáticos comunes, aun cuando se presente afebril y sin signos neurológicos.

\section{REFERENCIAS BIBLIOGRÁFICAS}

I. Almeer G,Azzopardi C, Kho J, et al.Anatomy and pathology of facet joint. J Orthop. 2020 Apr 8;22: I09-II 7.

2. Narváez J, Nolla JM, Narváez JA, et al. Spontaneous pyogenic facet joint infection. Semin Arthritis Rheum. 2006 Apr;35(5):272-83.

3. Halpin D, Gibson R. Septic arthritis of a lumbar facet joint. J Bone Joint Surg Br. 1987;69-B::457-9.

4. Yoon J, Efendy J, Redmond MJ. Septic arthritis of the lumbar facet joint. Case and literature review. J Clin Neurosci. 2020 Jan;7I:299. 303.

5. Felix E. Diehn, Felix. Imaging of Spine Infection. Radiologic Clinics of North America, 20I 2. 50(4):777-798.

6. Moritani T, Kim J, Capizzano A, et al. Pyogenic and non-pyogenic spinal infections: emphasis on diffusion-weighted imaging for the detection of abscesses and pus collections. Br J Radiology. 20I4;87(I04I). Publicación online: doi.org/I0.1259/bjr.201400 I I

7. André V, Pot-Vaucel M, Cozic C, et al. Septic arthritis of the facet joint. Med Mal Infect. 20 I 5 Jun;45(6):2I 5-2I.

8. Doita M, Nabeshima Y, Nishida K, et al. Septic arthritis of lumbar facet joints without predisposing infection.J Spinal Disord Tech. 2007 Jun;20(4):290-5.

9. Muffoletto Anthony J, Ketonen Leena M, Mader Jon T, et al. Hematogenous pyogenic facet joint infection. Spine 200I;26(I4):1570-6..

10. Butler J, Shelly, Martin, Timlin M, et al. Nontuberculous pyogenic spinal infection in adults. Spine. 2006;3I (23):2695-2700.

II. Ergan M, Macro M, Benhamou CL, et al. Septic arthritis of lumbar facet joints: a review of six cases. Rev Rhum Engl Ed. 1997;64:386-95

12. Cheung WY, Luk KDK. Pyogenic spondylitis. Int Orthop. 2012;36:39740.

13. Michel-Batôt C, Dintinger H, Blum A, et al.A particular form of septic arthritis: septic arthritis of facet joint. Joint Bone Spine. 2008 Jan;75(I):78-83.

14. Rajeev A, Choudhry N, Shaikh M, et al. Lumbar facet joint septic arthritis presenting atypically as acute abdomen - A case report and review of the literature. Int J Surg Case Rep. 2016;25:243-245.

15. Bureta C, Tominaga H, Yamamoto T, et al. Lumbar spine epidural abscess and facet joint septic arthritis due to Streptococcus agalactiae: a case report. BMC Surg. 2018 Mar 13;18(I): I6.

\section{CORRESPONDENCIA:}

Aland Bisso

albian44@yahoo.es

Fecha de recepción: 05-07-2021.

Fecha de aceptación:

Conflicto de interés: ninguno, según el autor.

Financiamiento: por el autor. 